A post mortem examination discovered in the brain traces of foregone subacute inflammation; and there were also, in the lungs, the remains of previous inflammatory action.

\section{ON THE TREATMENT OF SCALDS OF THE GLOTTIS.}

By John Slodxe, M.D., Leicester.

Dunisg a residence of seven years and a half in two large county hospitals, I have seen six cases of scald of the glottis in children, from attempts to drink boiling water from the spout of a kettle. As, in five of these cases, the untoward symptoms which result from this injury appeared to me to be effectually controlled by the treatment adopted, I believe I shall do some service by directing the attention of the profession to it. I shall briefly describe all the cases which have fallen under my observation.

Case I. Scald of the Glottis succeeded by urgent Dyspnoa: Traclicotomy: Pneumonia: Death. Dec. 27 th, 1852. Robert Jolnson, aged 3 years, of Radford, was admitted into the General Hospital, Nottingham, under the care of Mr. Eddison. The child was stated to have very recently attempted to drink boiling water from the spout of a kettle. The breathing was easy. The mucous membrane of the mouth was congested, and over the posterior parts there was a number of white patches. He was ordered to take every two hours a teaspoonful of a saline mixture containing one-sixteenth of a grain of tartar emetic; also every two hours a grain of calomel; an hour to intervene between the dose of the mixture and the powder. About three hours after admission, rapidly increasing dyspnos came on, with crowing inspiration and some lividity of lips and countenance. He was ordered to have the air which he breathed saturated with steam. This was accomplished by putting the child in a small ward, in which water was boiled in an open vessel, the steam from which escaped into the apartment. Six hours after admission, the dyspnœa having become very urgent, Mr. Eddison performed tracheotomy, making the opening in the upper rirgs of the windpipe. A tube having been inserted, a considerable quantity of tough mucus was expelled, and in a few minutes the patient was asleep. Flannels, wrung out of hot water, were placed over the opening; and the medicines were omitted.

Dec. 28th. He slept soundly during the night. Some mucous râles were audible over the chest. On attempting to swallow a little tea, it was returned by the nares. He was ordered to have injections of beef-tea every six hours.

Dec. 29th. The patient swallows greedily. The mucous râles are diminished. The enemata were omitted. $\mathrm{He}$ was ordered to have beef-tea and a mixture of tea and milk.

Dec. 31st. The tube was removed. Moist crepitation was heard all over the chest. He takes his beef-tea well.

Jan. 6th, 1853. He progressed favourably till last night, when the effusion into the bronchi became much increased, accompanied with considerable dyspncen. Steam was con. stantiy poured into the room, apparently with much benefit.

Jan. 7th. He was much better.

Jan. 10th. The dyspnœa increased very much in the night. The opening was enlarged downwards, without relief. He died to-day.

The dissection revealed considerable congestion of the epiglottis, larynx, trachea, and bronchial tubes, with splenisation of the middle lobe of the right lung, and of the antero-inferior border of the left. The lower lobe of the right lung was much congested, and did not crepitate on pressure. A copious effusion of mucus was found in the bronchial tubes.

CASE II. Scald of the Glottis : Urgent Dyspnoa : Recovery. March 24th, 1851. Robert Payne, aged 2 years, was admitted into the General Hospital, Nottingham, having an hour previously attempted to drink boiling water from the spout of a kettle. On admission, his breathing was slightly croupy in character. He was ordered to take a grain of calomel every hour; and a saline mixture, containing one-sixteenth of a grain of tartar emetic, every two hours. About three hours after admission, four leeches were applied to the front of the neck. About four hours after he was brought to the hospital, the dyspnœa had become very urgent, and Mr. White was consulted about the propriety of performing tracheotomy. He refused to sanction this operation, stating that death almost invariably resulted; whereas cases submitted to the treatment being carried out in this child frequently recovered. Twelve hours after the accident had happened, Mr. White, the house. surgeon, was called to see the boy; and the breathing was then so very difficult that $\mathrm{Mr}$. White considered him in a hopeless state. He, however, shortly after began to improve; and, on the 26 th, the breathing was still crowing, but much easier than on the preceding day. On the 29th, he was discharged, quite well.

CASE IIr. Scald of the Glottis : Dyspnoa : Recovery. March 15th, 1856. Sarah Collins, aged 3 , was admitted into the Leicester Infirmary, under the care of Mr. Paget, having five minutes previously attempted to swallow some boiling water from the spout of a kettle. Some grey patches were visible on the inside of the mouth. The breathing, on admission, was quite easy. She was merely ordered to take a little saline nixture every two hours. At milnight, six hours after admission, I was called to see her; and the breathing was now difficult and noisy. There was no lividity of the lips, or of the countenance. She was ordered to have three leeches over the larynx, to take a grain of calomel every hour, and one-twelith of a grain of tartar emetic with each dose of the mixture.

March 16th. She was sick after the first doses of the antimony. The dose was therefore diminished to one-sixteenth of a grain. The child was allowed beef-tea and milk ad libitum.

Nothing worthy of note subsequently occurred; and, on the 18th, she was discharged cured.

CASE Iv. Scald of Glottis : Dyspnœa: Recovery. Jan. 13th, 1858. S. Johnson, aged $2 \frac{1}{2}$ years, was admitted into the Leicester Infirmary, under the care of $\mathrm{Mr}$. Paget. 'Tlie patient, a healthy boy, about an hour before admission drank some hoiling water from the spout of a tea-kettle. 'Ihe water was "steaming hot". He spat it out, and rolled on the floor, screaming. On admission, his breathing was easy. His mouth was not examined. He was ordered to take a grain of calomel every hour, and one-sixteenth of a grain of tartar emetic in a saline mixture every two hours. He was admitted at six o'clock in the evening.

Jan. 14th. I saw him at midnight. His breathing was then slightly laboured and noisy. Between one and two o'clock this morning, he began to vomit; and, during the next four hours, he vomited three times. About six o'clock, the bowels were well cleared out. After my midnight visit, the mother informs me that his breathing became gradually more noisy and laboured till about six, when it was quite croupy. He then began to improve; and his breathing at noon this day was perfectly easy. In the evening, he was discharged cured.

CASE v. Scald of the Glottis: Treatment by Calomel and Antimony: Dyspnoa thirty hours after the Accident, the Calomel having been previously omitted: Recovery. March 20th. Alice Hill, aged 3, was admitted into the Leicester Infirmary, under the care of Mr. Paget, having drunk some boiling water from the spout of a tea-kettle. She had been always a healthy child, but, for a week previously to the accident, was rather "feverish", although able to go to school. The child was ordered the calomel and antimony, as in the preceding case.

March 21st. The breathing is perfectly easy, and the child seems quite well. After the medicine had been taken twelve hours, it caused sickness. For urgent reasons, the mother was allowed to resnove her child from the Infirmary. The calomel was ornitted, but the antimony was continued.

March 22nd. At twelve o'clock last night the breathing began to be laboured, and it has since been gradually becoming worse. The respirations are forty in the minute, loudly sigh. ing, sometimes slightly crowing. The eyelids are half closed, the head is moved forwards with each inspiration. There is no lividity of the countenance; no cough. She has had no antimony since three o'clock this morning, as her supply of medicine had become exhausted. She was readmitted. The calomel and antimony were repeated, as at first.

March 23rd. The breathing this morning was perfectly easy: She remained in the Infirmary for seven days longer, on account of an attack of diarrhœa. She was then discharged, cured.

CASE vi. Scald of the Glottis : Dyspnoa: Recovery November 28 th. Elizabeth Smith, aged $3 \frac{1}{2}$ years, was admitted yesterday into the Leicester Infirmary, under the care of $\mathbf{M r}$. Paget. She is a healthy, well developed child, who had had no previous illness. Yesterday, she attempted to swallow boil. ing water from the spout of a kettle. She began to have noisy breathing about five hours afterwards. When she was brought to the Infirmary, four hours after the commencement of the dyspnœa, the breathing was s!ightly crowing, and difficult. Three leeches were ordered to be applied at the upper part of the sternum, and a grain of calomel was prescribed, to be 
taken every hour, and one-twelfth of a grain of tartar emetic every two hours. These remedies were ordered about nine o'clock in the evening.

November 29th. The symptoms had quite disappeared. The medicine made the child vomit once, about twenty-four hours after she began to take it. To-day she was ordered to take the remedies only half as frequently as on admission.

November 30th. She appeared to be free from all danger, and was discharged, cured.

Fiemanks. Of these six cases, it will be observed that the only one which ended fatally was that in which tracheotomy was performed, and the dyspnœa was never so urgent in this case as in that of Payne, who recovered. According to $\mathrm{Mr}$. Wright of Nottingham, who is a surgeon of great experience, tracheotomy in scalds of the glottis almost invariably results in death; and the treatment by leeching, calomel, and antimony, is frequently successful. In the Medical Times and Gazctte, there was lately published a report of fourteen cases of scalds of the glottis in which tracheotomy was adopted. If we add to these fourteen the case which I have published, and another which occurred about two years ago in the Dis. pensary of this town, and which ended fatally, we have sixteen cases of scalds of the glottis in which tracheotomy was resorted to, and, of these, no fewer than thirteen ended fatally, and " in one of the cases which recovered, from certain peculiarities in the history, there is quite room for doubt as to whether the boil. ing water had ever reached the glottis". These facts are in accordance with $\mathrm{Mr}$. Wright's statement, that tracheotomy in scalds of the glottis almost invariably ends in death, and, as far as my observetion has extended, the other part of his state. ment is equally correct, in which he avers that the treatment by calomel, antimony, and leeching is frequently successful. In five of the six cases I publish it was successful, and, I believe, if tracheotomy had not been adopted in the remaining case, it would have been successful in this also.

In scalds of the glottis, I believe it is the best course to commence treatment by calomel and antimony as soon as the accident has happened, although dyspnœa may not be present, and to continue the treatment for forty eight hours, gradually diminishing the doses for the last twenty-four hours. By the early adoption of the treatment the dyspncea may be prevented, or at least mitigated; at all events no harm is likely to ensue from this course. Case v. shows the danger of omitting the remedies, especially the calomel, too soon.

\section{CASE OF TETANUS INFANTUM.}

\section{By I. Harrinson, Esq., F.R.C.S., Fellow of the Obstetrical Society.}

[Real beforc the Reading Pathological Society, October 12th, 1859.]

Mrs. Searle, Orchard Street, aged 24, was delivered of her third child on Friday morning, September 2nd, 1859. It was a male child, fine and apparently healthy in every respect. From Friday till Wednesday all was well. The cord separated on Tuesday, the fifth day. On Wednesday, the child was restless, cried, and kicked. On Thursday, the mother reported that it cried all day; could not open its mouth; could not suck; and frequently stretched, and was stiff.

Next day (Friday), I saw it. Every few minutes it appeared as if struck by an electric shock; every muscle was thrown into distorted action.

I will not attempt to describe. This drawing tells the wrinkled forehead; the elevated brow; the closed eye; the dilated nostril ; the rigid masseter; the fixed jaw; the closed mouth; the corrugated lips; the bubbling saliva; the retracted head; the shortened neck; the starting cervical muscles; the turgid veins; the arched spine; the raised chest; the troubled breathing; the catching diaphragm ; the heaving abdomen; the separated arm; the squared elbow; the bent wrist; the clenched fingers; the incurved thumb; the extended and separated legs; the bent down toes; the livid surface; the whole figure rigid as wood-a pitiful sight.

The paroxysm was renewed by a slight noise, the gentlest ouch. A placid interval of a few minutes succeeded, and then unother fit followed.

On inquiry, I could make little out as to predisposing causes, rr anything favouring the development of such a disease. The nother was healthy; the labour said to be hard, of eighteen lours duration, conducted by a midwife; the child vigorous, at ihe full period; milk abundant; the after care better than in nost of her class; her room small, but unusually clean; no exposure to cold; and there was no surrounding source of noxious agency discoverable.

On examining the child, the umbilicus was seen prominent, at least half an inch long, red, and showing an unhealthy suppurating surface. At this time, there was no alteration in the colour of the skin.

The treatment consisted in having a large poultice constantly on the umbilicus; in warmth, quiet, and getting down as much milk, with a small portion of brandy, as possible. There were intervals, few and far between, in which a fair quantity could be administered. The medicine consisted of magnesia, syrup of poppies, assafœetida, and some aromatic water occasionally given.

I shall not attempt a daily report, as one day's detail differed little from its fellow. The umbilicus continued to discharge till within two days of its death. The secretions were normal throushout. Emaciation rapidly advanced; the skin assumed a brownish hue, and hung in shrivelled folds of leathery texture. Peace and pang pursued their sickening interchange. The child gradually became more feeble; and on the tenth day of the disease, and the fifteenth of its existence, it sank by degrees exhausted.

Post Morten Examination, performed by Mr. George May. Only the abdomen was examined. The umbilicus had gained its usual appearance; nothing morbid was found. The umbilical vein was pervious, and contained a thin bloody fluid. The umbilical arteries were also pervious, but in a less degree than the veins.

Rentarks. Tetanus neonatorum used to be a common disease; now it is very rare. It was an hospital disease, and usually fatal. In the Dublin Lying-in Hosyital, it is said to have killed at one time 17 per cent. ; and that better ventilation reduced this remarkable fatality to 5 per cent.

I need not go into the numerous causes, predisposing and exciting, supposed to have to do with the production of this disease. Confining myself to the class of cases under consideration, I may quote Dr. Copland, who says, "In connexion with the division of the umbilical cord, an impure air, etc., may concur in developing the malady in those constitutionally predisposed to it."

It may here be remarked, that the necessity for a wound of any kind is not absolute for the production of tetanus. Sir Charles Bell says: "In the West Indies, it is produced from exposure to the night air, and most probably from exhalations from the ground. Tetanus is epidemic in Brazil." Most writers believe that the cord has something to do with the origin of tetanus, but they don't know what: all speak indefinitely, except Professor Colles (quoted by Evanson and Maunsell), who shrewdly remarks: "A vitiated state of the atmosphere operates by inducing an unhealthy or unkindly form of inflammation or ulceration at the navel; and that the disease is, in fact, a species of traumatic tetanus, having its immediate cause in the wound occasioned by the separation of the cord." I maintain, with Dr. Colles, that a festering navel is the fons et origo of tetanus infantum. I do not say that tetanus is the only disease that may arise from a festering navel. For example, Mrs. W.'s infant was born before I arrived, and the cord was tied by the nurse; how, I do not know. I did not see it. The child was healthy in every respect. All was well till the morning of the sixth day, when the nurse said it began to look "sorry". On this day the cord came off. I saw it in the evening. It had a grievous look-sunken-clearly from grave mischief. The umbilicus was festering; abdomen distended and hard. It died on the eighth day. Post mortem examination, the umbilicus was red and prominent. There was universal peritonitis. The liver was wholly covered by false membrane.

Speaking from my own limited experience, bruised un healthy wounds are those that favour tetanus. They have been present in two other cases which have occurred to me.

A tradesman, living in Minster Street, aged 31, was thrown out of a pony carriage. He fell on his knees, which were much bruised and wounded, leaving angry sores. Tetanus supervened on the fifteenth day; he died on the nineteenth.

I saw, with MIr. Luce, a boy aged 8 years, whose fingers had been smashed in an agricultural machine. Tetanus came on on the fourteenth day; he died on the nineteenth.

Short notes of the following two cases were taken, because of their recovery. A malignant tumour was removed by $\mathrm{Mr}$. Fergusson, from the tibia of a man, aged 20 . On the 20th day afterwards, tetanus appeared. $\mathrm{He}$ got well. Opium, croton oil, and quinine were used. (Dritish Medical Joursal, October 3rd, 185\%.)

A girl, aged 7 years, was admitted into St. George's Hospital 